Article

\title{
A Dual-Band Rectifier for RF Energy Harvesting
}

\author{
Ekkaphol Khansalee $^{1}$, Kittipong Nuanyai ${ }^{2}$, and Yan Zhao ${ }^{1, *}$ \\ 1 International School of Engineering, Faculty of Engineering, Chulalongkorn University, Bangkok, \\ Thailand \\ 2 Faculty of Industrial Technology, Phetchaburi Rajabhat University, Phetchaburi, Thailand \\ *E-mail: yan.z@chula.ac.th
}

\begin{abstract}
Our cities are surrounded by a large number of radio frequency (RF) signals broadcasted by various wireless systems. In order to enhance the efficiency of energy usage in addition to the purpose of communication, ambient RF energy harvesting systems are designed to harvest and recycle wireless energy for many applications such as battery chargers, sensor devices and portable devices. The main element of the ambient RF energy harvesting system is a rectenna which is the combination of an antenna and a rectifying circuit. Even though the ambient RF energy is widely broadcasted by many systems, the energy is extremely low. Therefore, high performance antenna and rectifying circuits have to be designed for supporting small incident power; also the number of frequency channels of the rectenna can enhance the performance and support different harvesting locations. This paper proposes a dual-band rectifier for RF energy harvesting which is designed to operate at $2.1 \mathrm{GHz}$ and $2.45 \mathrm{GHz}$. The first channel can provide the maximum efficiency of $24 \%$ with $1.9 \mathrm{~V}$ of the output voltage at $10 \mathrm{dBm}$ of input power. On the other hand, a maximum efficiency of $18 \%$ and $1.7 \mathrm{~V}$ of the output voltage can be achieved by the second channel at $10 \mathrm{dBm}$ of input power.
\end{abstract}

Keywords: RF energy harvesting, rectenna, rectifier, voltage doubler, Schottky diode.

ENGINEERING JOURNAL Volume 19 Issue 5

Received 15 June 2015

Accepted 3 July 2015

Published 31 October 2015

Online at http://www.engj.org/

DOI:10.4186/ej.2015.19.5.189 


\section{Introduction}

Recently, energy harvesting at radio frequency (RF) has been a fast growing topic. Since the first wireless energy transmission was proposed and demonstrated in the 1890's by Nikola Tesla using the electromagnetic wave propagation technique of Hienrich Hertz [1, 2], the topic is developed and applied to many applications such as microwave-powered helicopter prototype, solar power satellite system (SPSS), microwave power transmission in space and radio-frequency identification (RFID) [3-8]. The RF energy harvesting is developed by the wireless energy transmission technique for harvesting and recycling the ambient RF energy which is widely broadcasted by many wireless systems such as mobile communication systems, Wi-Fi base stations, wireless routers, wireless sensor networks and wireless portable devices. In order to extend the battery life and avoid using battery, the RF energy harvesting has been applied to be a rechargeable circuit and a small power supply for portable devices and tiny devices such as mobile phones, tablet, sensor devices and biomedical implants [3,9]. Although a lot of wireless systems broadcast into the environment, the power density of ambient RF energy is very low which makes it challenging to design a rectenna for harvesting a sufficient amount of energy.

A rectifier and an antenna are combined to form a rectenna which was initially designed by Brown for converting the microwave power to be direct current (DC) power $[3,10]$. Therefore, the main element of an RF energy harvesting system is the rectenna that detects the ambient RF energy by the antenna and converts the received energy to be the DC power by the rectifier circuit, as shown in Fig. 1.

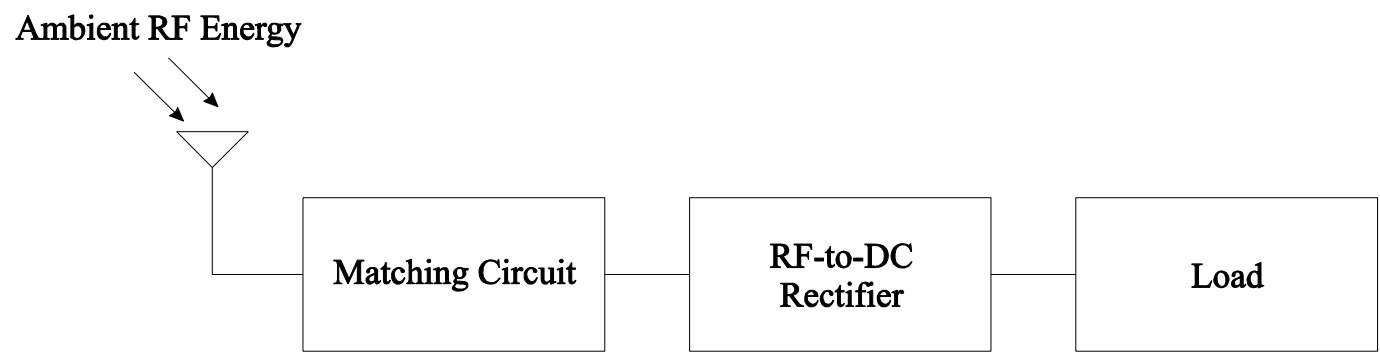

Fig. 1. Block diagram of an ambient RF energy harvesting system.

To achieve the high RF-to-DC power conversion efficiency for RF energy harvesting, high gain and wideband antennas must be designed to increase the power density and harvest as much as possible the ambient RF energy. On the other hand, the rectifier circuit has to be implemented to provide a high efficiency in RF-to-DC power conversion and support multiband for obtaining high DC power from various frequencies.

In this paper, a dual-band rectifier is proposed to support the RF energy harvesting at $2.1 \mathrm{GHz}$ and $2.45 \mathrm{GHz}$ that are UMTS-2100 and Wi-Fi operating frequencies, respectively. In order to harvest at both frequencies, the input matching of the rectifier is designed to provide the high conversion efficiency at both frequencies; also a high sensitivity Schottky diode is selected to be a small signal detector for the rectifier circuit, as shown in section 2. The simulation and experimental results are compared and discussed in section 3. Finally, the summary of the proposed design is concluded in section 4.

\section{Dual-Band Rectifier Circuit Design}

The rectifier circuit is designed by Greinacher voltage doubler topology that is a good candidate for ambient RF detection. Furthermore, the Schottky diode was selected to support the fast switching of the high frequency of the incident signal. To determine the optimum input impedance and design an input impedance matching of the rectifier circuit, the Advance Design System (ADS) was chosen to be the simulator for this design.

\subsection{Diode Specifications}

To achieve the high efficiency in RF-to-DC conversion, the fast switching-time diode is a promising device to detect the ambient RF energy [11]; and the diode proposed in this design is Schottky diode HSMS-285C 
of Avago Technology. The diode has been developed for low cost and small signal applications $\left(P_{\text {in }}<-20\right.$ $\mathrm{dBm})$, and it has two detector diodes inside which are connected in series. Therefore, the device is suitable for use as a voltage doubler circuit. The diode is a zero bias Schottky diode that can provide low forward voltage $\left(V_{f}\right)$ from $125 \mathrm{mV}$ to $250 \mathrm{mV}, 3.8 \mathrm{~V}$ of break-down voltage $\left(V_{b}\right), 25$ Ohms of series resistance $\left(R_{s}\right)$, and $0.18 \mathrm{pF}$ of zero bias junction capacitance $\left(C_{j 0}\right)$. From the prominent properties of the diode, it is suited in the proposed circuit.

\subsection{Schematic of Rectifier Circuit}

The rectifier consists of three parts which are input matching, voltage doubler circuit and load resistance $R_{L}$, as shown in Fig. 2.

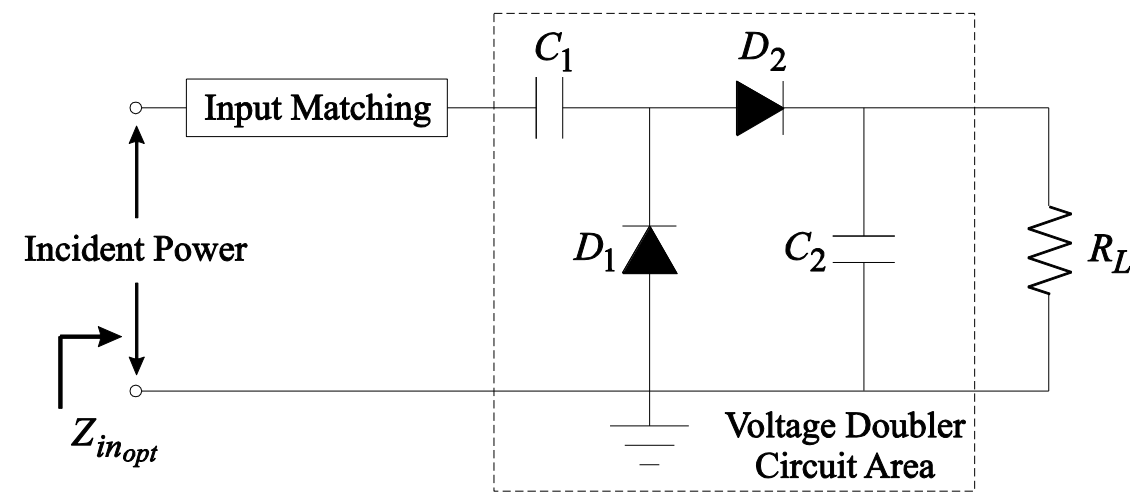

Fig. 2. Schematic diagram of the RF-to-DC rectifier circuit with voltage doubler circuit.

The full-wave peak-to-peak voltage of the incident RF signal $\left(V_{i n}\right)$ is rectified by the voltage doubler circuit that consists of a voltage clamp $\left(D_{1}\right.$ and $\left.C_{1}\right)$ and a peak rectifier $\left(D_{2}\right.$ and $\left.C_{2}\right)$ [12]. On the negative half-cycle of the incident signal $\left(V_{i n^{-}}\right)$, the current flow through $D_{1}$ and it was stored by $C_{1}$ while $D_{2}$ is cutoff. The voltage across $D_{1}$ is nearby its threshold voltage $\left(V_{t h 1}\right)$, thus the stored voltage of $C_{1}$ $\left(V_{C_{1}}\right)$ can be determined by Eq. (1):

$$
V_{C_{1}}=V_{i n^{-}}-V_{t h 1}
$$

On the positive half-cycle of the incident signal $\left(V_{i n^{+}}\right), D_{1}$ is cutoff while $D_{2}$ is turned on by the twice incident signal that is combined by the stored voltage of $C_{1}$ and the positive half-cycle. Therefore, the output voltage $\left(V_{\text {out }}\right)$ of the circuit can be calculated by Eq. (2):

$$
V_{\text {out }}=2 V_{\text {in }}-V_{\text {th } 1}-V_{\text {th } 2}
$$

In order to match the voltage doubler circuit with the standard antenna port of $50 \mathrm{Ohms}$, the sourcepull technique is used to determine the optimum input impedance $\left(\underline{Z}_{\text {in opt }}\right)$ for converting the optimum performance for the circuit [13]. The source-pull technique can be applied to determine the optimum point by sweeping input impedance. The performance of the circuit can be determine by the efficiency of the RFto-DC power conversion $(\eta)$ relative between the incident RF signal $\left(P_{i n}\right)$ at the input port and the DC output power $\left(P_{o}\right)$, as in Eq. (3). The DC output power $\left(P_{o}\right)$ can be calculated by the multiplication of DC output voltage $\left(V_{o}\right)$ and DC load current $\left(I_{o}\right)$.

$$
\eta(\%)=\frac{P_{o}}{P_{\text {in }}} \times 100
$$




$$
P_{o}=V_{o} \times I_{o}
$$

\subsection{Design Methodology}

The design methodology can be summarized as follows:

- Connect the HSMS-285C with the DC-filter capacitors and the assumed load resistance $R_{L}$ in the form of voltage doubler circuit, as shown in Fig. 2.

- Determine the optimum input impedance of the voltage doubler circuit for the two operating frequencies by the source-pull technique. From the simulation result, the input impedance is $\underline{Z}_{\text {inopt }}=60.077-j 116.184$.

- Create the input matching for the voltage doubler circuit that is matched to $\underline{Z}_{\text {inopt }}$ and 50 Ohms of input port at the desired frequencies.

\section{Simulation and Experimental Results}

The proposed circuit was designed and simulated in ADS to predict its performance before fabrication. The simulated schematic diagram is shown in Fig. 3 that consists of 50 Ohms of input termination, multi-stub matching, the voltage doubler circuit, DC-filter capacitor and the load resistance termination.

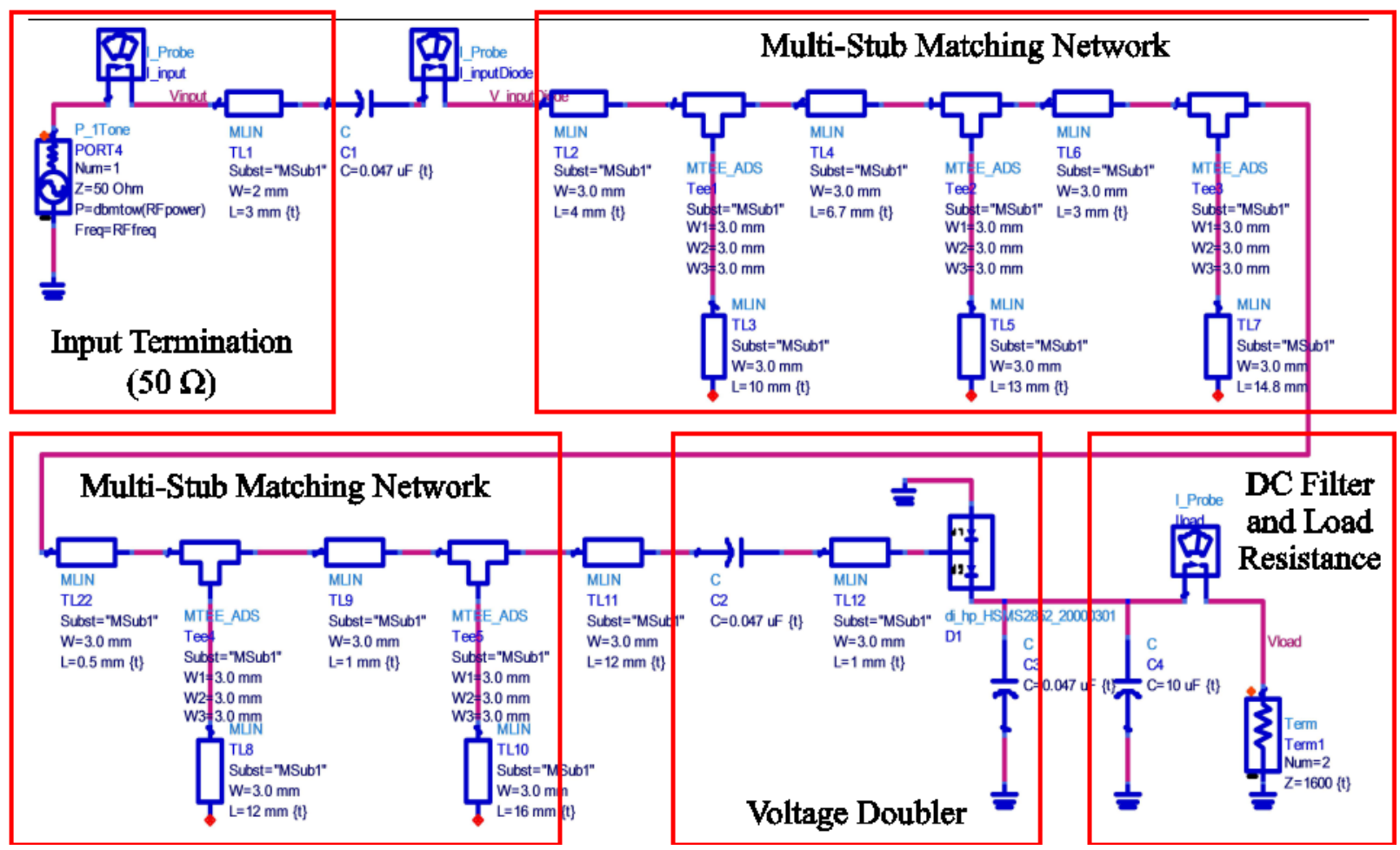

Fig. 3. ADS simulation schematic of the dual-band rectifier circuit.

The prototype was fabricated on a low cost FR-4 substrate with a dielectric constant $\left(\varepsilon_{r}\right)$ of 4.3 and thickness $(\mathrm{H})$ of $1.6 \mathrm{~mm}$. The dimension of the circuit is $70 \times 35 \mathrm{~mm}^{2}$. The multi-stub was designed to be input matching of the voltage doubler circuit that consists of HSMS-285C and DC-filter capacitors, as shown in Fig. 4. 

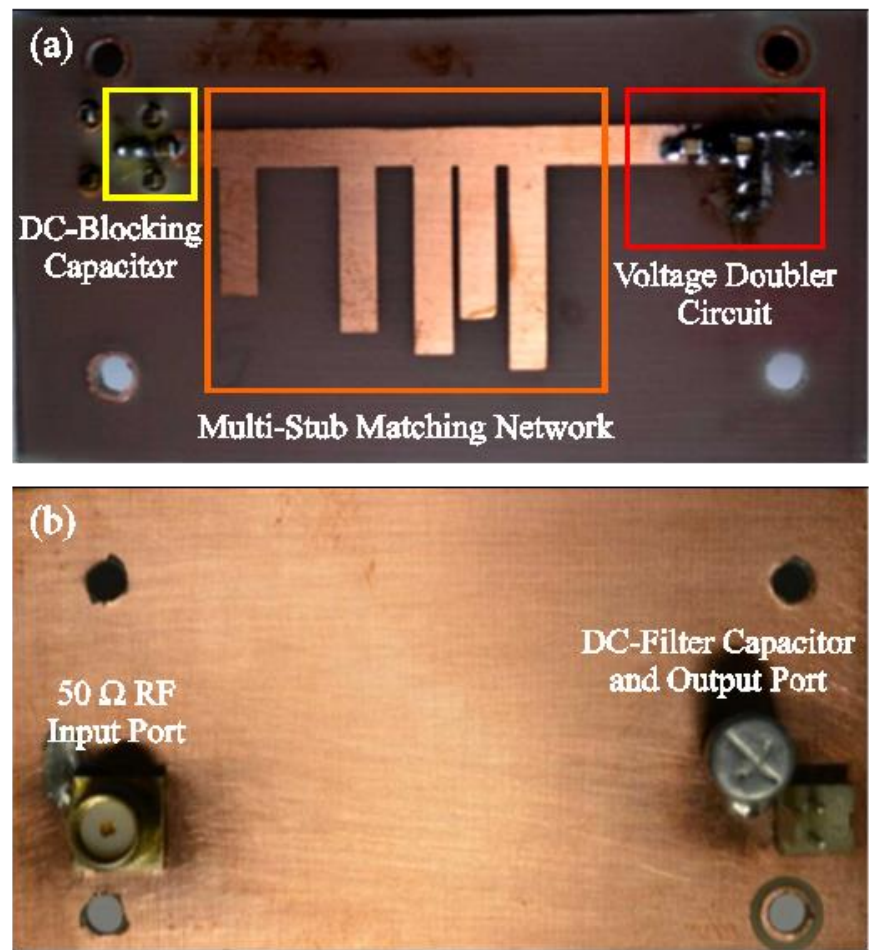

Fig. 4. Prototype of the dual-band rectifier circuit: (a) top view, (b) bottom view.

The performance testing system of the dual-band rectifier circuit was shown in Fig. 5. The main equipment of the system consists of the signal generator, digital multimeters and RF cables. The proposed prototype was fabricated with other designs, thus the circuit under test in Fig. 5 is bigger than the prototype. However, the circuits are not related to each other.

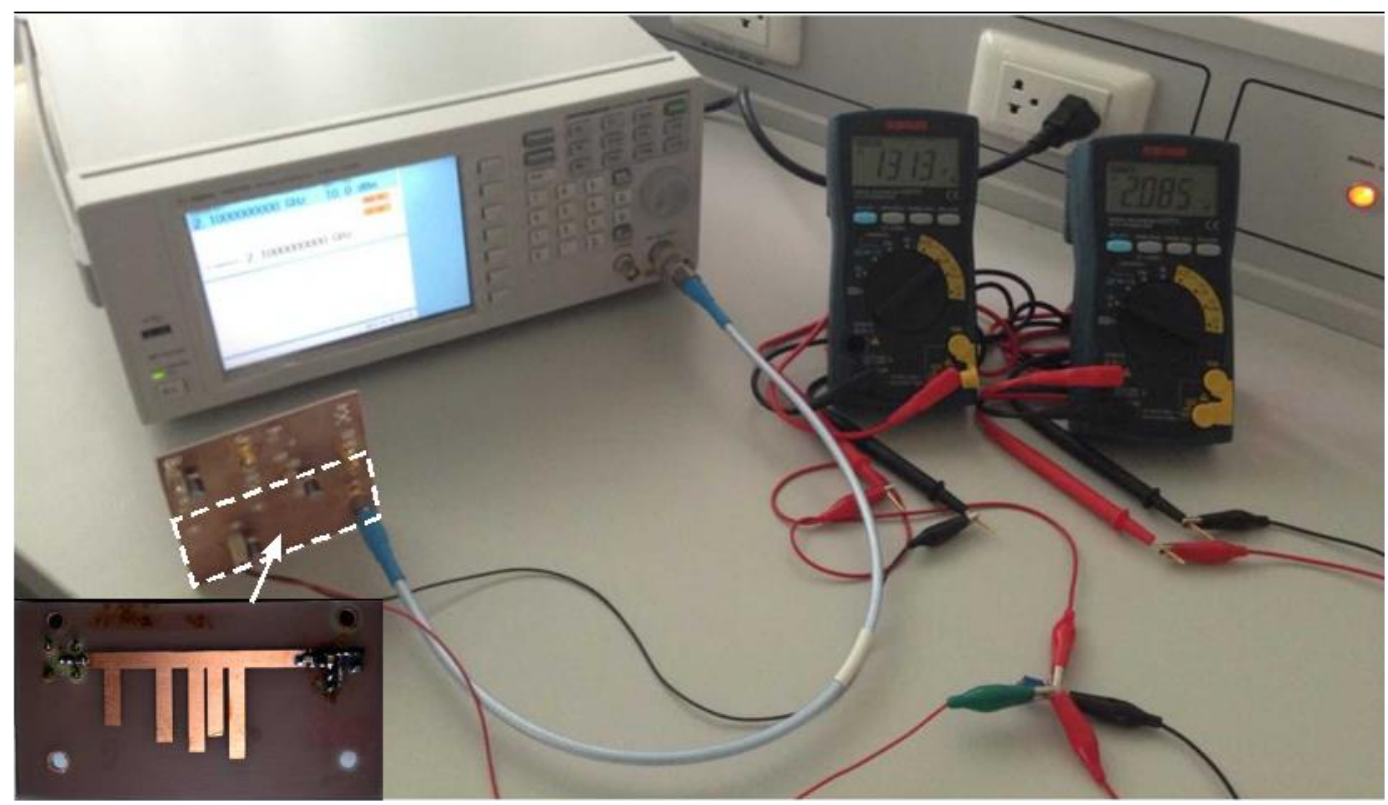

Fig. 5. The dual-band rectifier circuit under test with continuous wave input power at $2.1 \mathrm{GHz}$.

Figure 6 shows the simulation and measurement results of the input return loss. The simulation and measurement results were plotted by the solid square markers and the solid circle markers, respectively. At $2.1 \mathrm{GHz}$, the circuit can provide $-1 \mathrm{~dB}$ in the simulation result and $-5.7 \mathrm{~dB}$ in measurement. On the other hand, the minimum value of the simulation is $-12 \mathrm{~dB}$ and $-17 \mathrm{~dB}$ in the measurement result that can be achieved at $2.45 \mathrm{GHz}$. Considering in the broadband return loss, the measurement provides the results that is lower than $-10 \mathrm{~dB}$ from $2.4 \mathrm{GHz}$ to $2.49 \mathrm{GHz}$. 


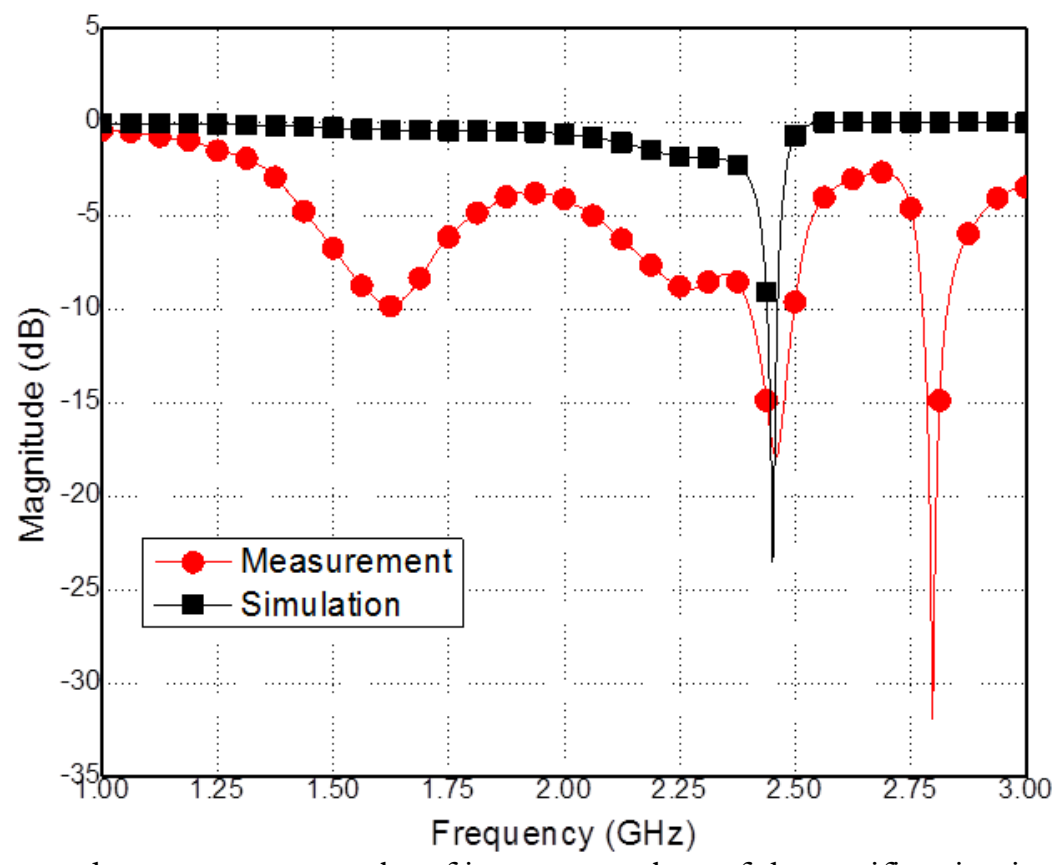

Fig. 6. Simulation and measurement results of input return loss of the rectifier circuit.

Figures 7 and 8 show the performance of the dual-band rectifier circuit at $2.1 \mathrm{GHz}$ and $2.45 \mathrm{GHz}$, respectively.

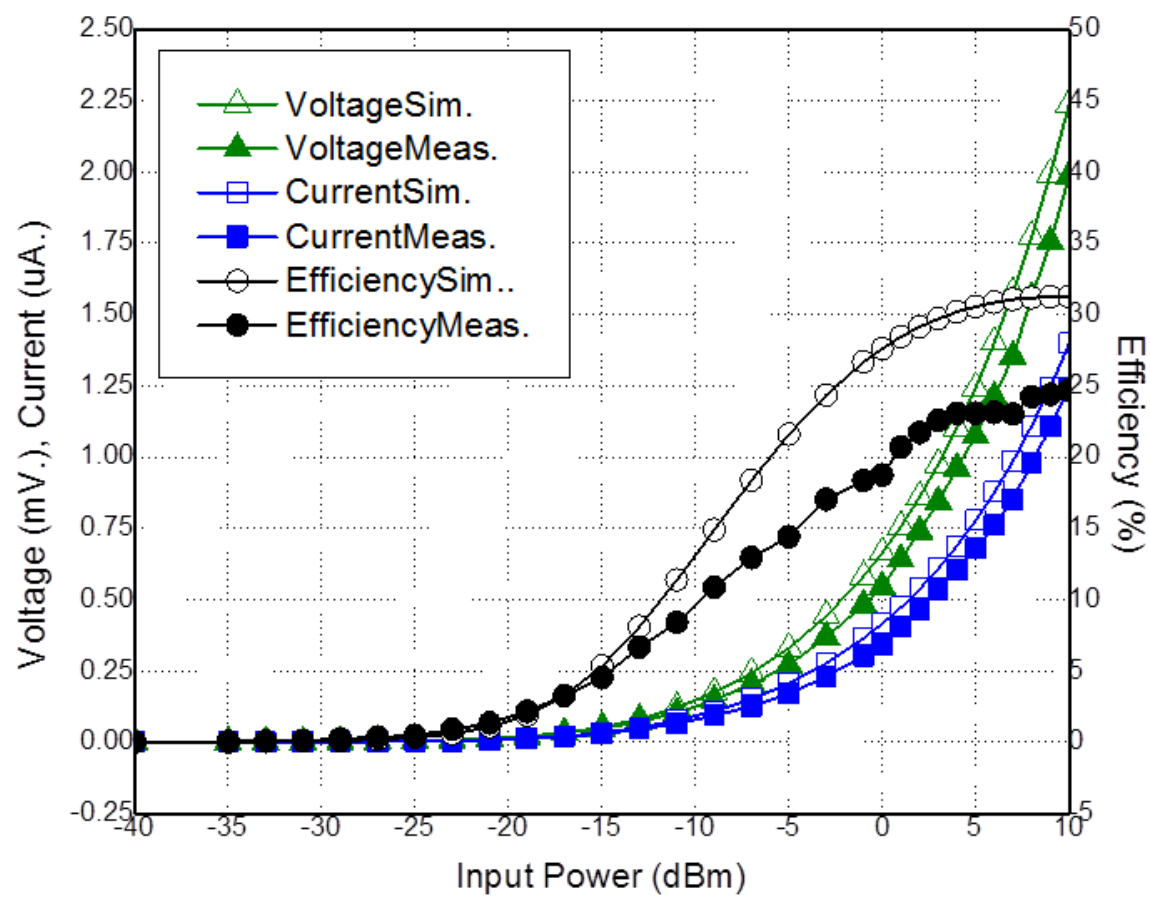

Fig. 7. Simulation and measurement results of DC output voltage, DC load current and efficiency versus continuous wave input power at $2.1 \mathrm{GHz}$. 


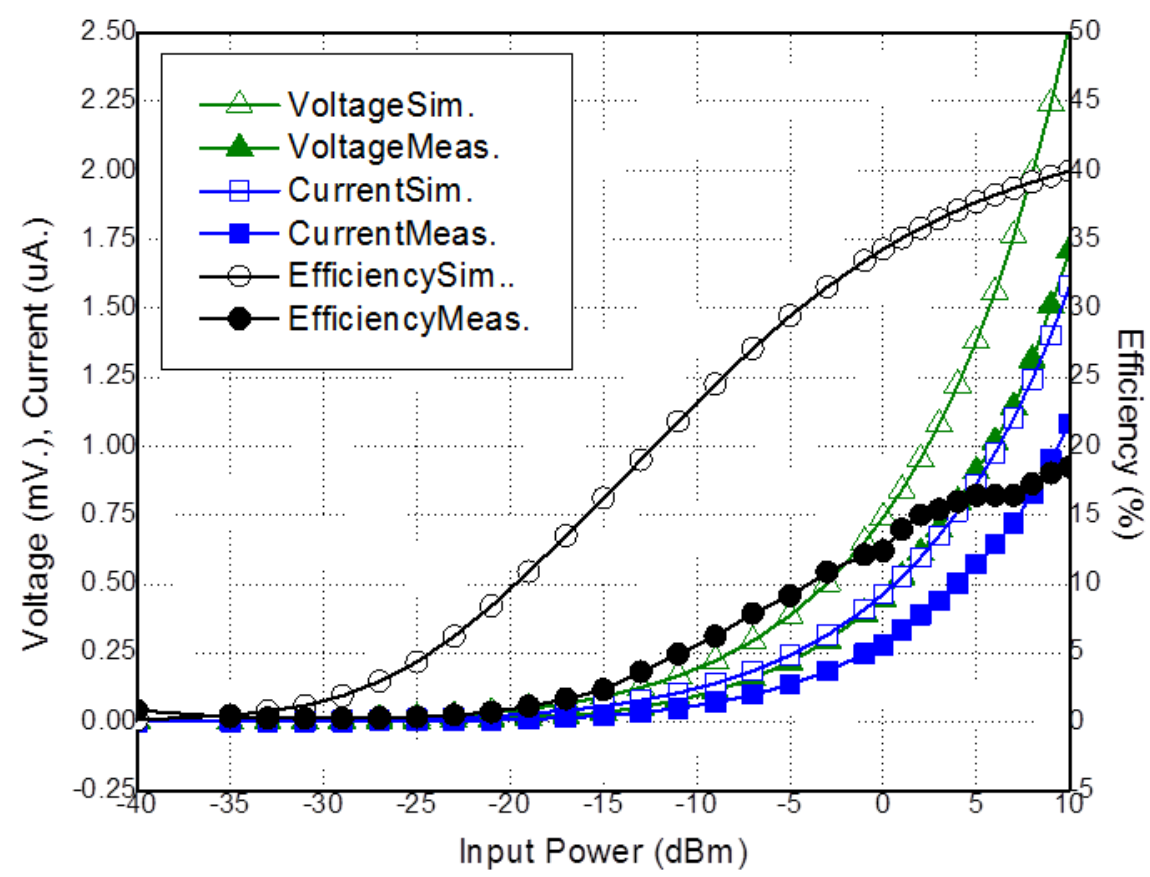

Fig. 8. Simulation and measurement results of DC output voltage, DC load current and efficiency versus continuous wave input power at $2.45 \mathrm{GHz}$.

The performance consists of the DC output voltage $\left(V_{o}\right)$, DC load current $\left(I_{o}\right)$ and efficiency $(\eta)$. The performance was measured by sweeping the input power $\left(P_{i n}\right)$ from $-40 \mathrm{dBm}$ to $10 \mathrm{dBm}$ at 1.6 $\mathrm{kOhms}$ of load resistance. The simulation results were plotted by transparent markers and the measurement results were illustrated by solid markers. The DC output voltage $V_{o}$, DC load current $I_{o}$ and efficiency $\eta$ were presented by triangle, square and circle markers, respectively. Even though the return loss of the 2.1 $\mathrm{GHz}$ is higher than $-10 \mathrm{~dB}$, the prototype can provide the maximum efficiency of $24 \%, 1.9 \mathrm{~V}$ of output voltage $V_{o}$ and $1.245 \mathrm{~mA}$ of load current $I_{o}$ at $10 \mathrm{dBm}$ of input power $P_{i n}$. At $2.45 \mathrm{GHz}$ of operating frequency, the maximum efficiency of $18 \%$ can be achieved at $10 \mathrm{dBm}$ of input power, also the maximum $V_{o}$ of $1.7 \mathrm{~V}$ and load current $I_{o}$ of $1.081 \mathrm{~mA}$ can be provided by the dual-band rectifier circuit. From all the above results, the difference between the simulation and measurement is generated by many parameters that are the parasitic parameters in the PCB and in the Schottky diode at high frequencies that can create higher parasitic impedance and higher error. This can be seen by that the error of efficiency at $2.1 \mathrm{GHz}$ is lower than the error at the $2.45 \mathrm{GHz}$. Moreover, the high performance do not come from only the good input matching, but also from the optimum input impedance like the $2.1 \mathrm{GHz}$ can provide performance better than the $2.45 \mathrm{GHz}$, although at $2.45 \mathrm{GHz}$ the rectifier is matched better than $2.1 \mathrm{GHz}$. Moreover, the circuit can support GSM-1800 that can convert the mobile to be DC voltage (1.7 V) while the mobile is calling, as shown in Fig. 9. 


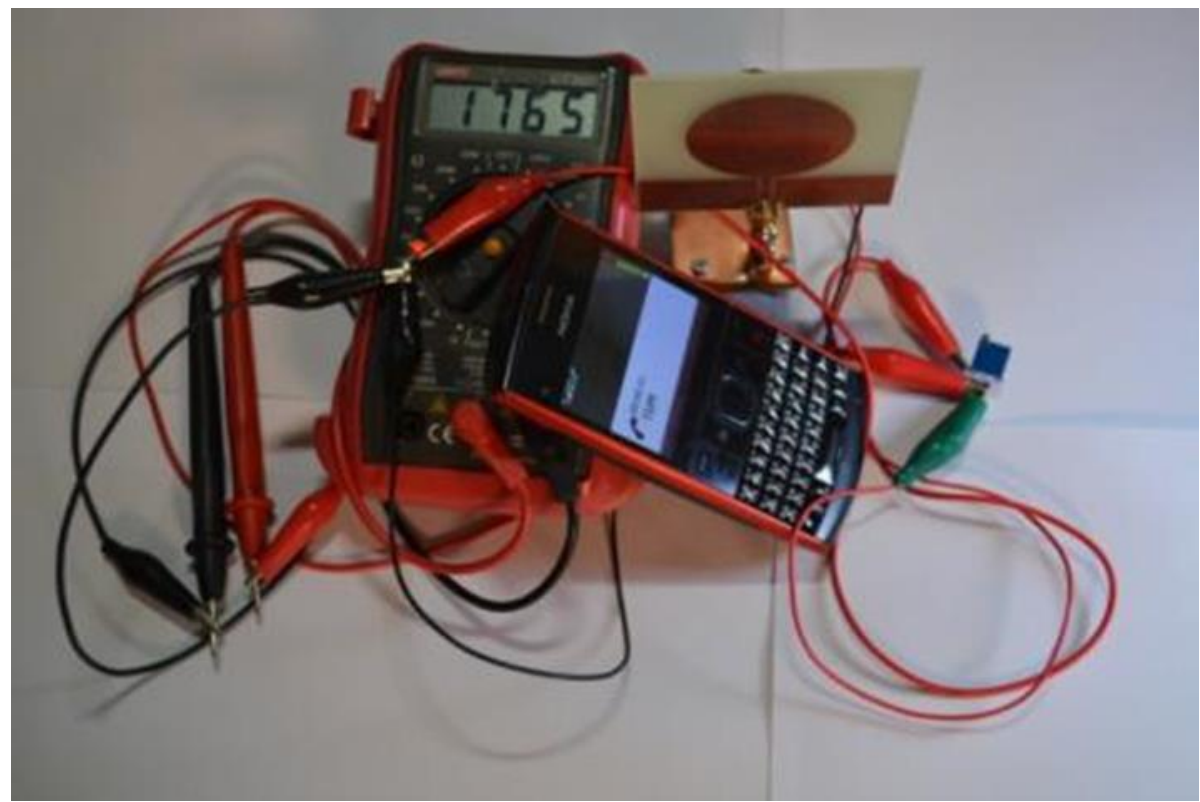

Fig. 9. The dual-band rectifier circuit under test with wideband antenna and GSM-1800 mobile phone.

\section{Conclusion}

In this paper, a dual-band rectifier for RF energy harvesting was presented. The proposed prototype was designed by voltage doubler topology for converting the RF signal to DC signal. In order to operate at high frequency and small input power application, the Schottky diode HSMS-285C was selected to be the detection elements in the RF-to-DC conversion topology. To achieve the optimum performance for the rectifying circuit, the source-pull technique was proposed to determine the optimum impedance for matching to $50 \mathrm{Ohms}$ of input port by the multi-stub matching that creates the broadband performance for the circuit. The proposed prototype provides the maximum efficiency of $24 \%$, the output voltage of $1.9 \mathrm{~V}$ and load current of $1.245 \mathrm{~mA}$ at $2.1 \mathrm{GHz}$ with $10 \mathrm{dBm}$ of input power. At $2.45 \mathrm{GHz}$, the maximum efficiency of $18 \%, 1.7 \mathrm{~V}$ output voltage and $1.081 \mathrm{~mA}$ load current can be achieved by $10 \mathrm{dBm}$ input power.

\section{Acknowledgement}

This research was funded by the Ratchadapisek Sompoch Endowment Fund (2014), Chulalongkorn University (CU-57-035-AM).

\section{References}

[1] A. S. Marincic, "Nikola tesla and the wireless transmission of energy," IEEE Transactions on Power Apparatus and Systems, vol. 101, no. 10, pp. 4064-4068, 1982.

[2] W. C. Brown, "The history of power transmission by radio waves," IEEE Transactions on Microwave Theory and Techniques, vol. 32, no. 9, pp. 1230-1242, 1984.

[3] S. B. Alam, M. S. Ullah, and S. Moury, "Design of a low power $2.45 \mathrm{GHz}$ RF energy harvesting circuit for rectenna," in 2013 ICIEV Conf., 2013, pp. 1-4.

[4] W. C. Brown, J. R. Minms, and N. I. Heenan, "An experimental microwave powered helicopter," in Proc. IRE Int. Conv. Rec, vol. 13, Part 5, 1965, pp. 225-235.

[5] P. E. Glaser, "Power from the sun," Science, no. 162, pp. 857-886, 1968.

[6] H. Matsumoto, "Microwave power transmission from space and related nonlinear plasma effects," The Radio Science Bulletin, no. 273, pp. 11-35, 1995.

[7] H. Matsumoto, "Research on solar power station and microwave power transmission in Japan: Review and perspectives," IEEE Microwave Magazine, vol. 3, no. 4, pp. 36-45, 2003.

[8] C. H. K. Chin, Q. Xue, and C. H. Chan, "Design of a 5.8-GHz rectenna incorporating a new patch antenna," IEEE Antennas and Wireless Propagation Letters, vol. 4, pp. 175-178, 2005. 
[9] H. Sun, Y. Guo, M. He, and Z. Zhong, "A dual-band rectenna using broadband Yagi antenna array for ambient RF power harvesting," IEEE Antennas and Wireless Propagation Letters, vol. 12, pp. 918-921, 2013.

[10] W. C. Brown, and J. F. Trinner, "Experimental thin-film, etched-circuit rectenna," IEEE MTT-S Int. Microwave Symp. Dig., pp. 185-187, 1982.

[11] G. Chaudhary, P. Kim, Y. Jeong, and J. H. Yoon, "Design of high efficiency RF-DC conversion circuit using novel termination networks for RF energy harvesting system," Microwave and Optical Technology Letters, vol. 54, no. 10, pp. 2330-2335, 2012.

[12] T. Le, K. Mayaram, and T. Fiez, "Efficient far-field radio frequency energy harvesting for passively powered sensor networks," IEEE Journal of Solid-State Circuits, vol. 43, no. 5, pp. 1287-1302, 2008.

[13] J. A. Hagerty, F. B. Helmbrecht, W. H. McCalpin, R. Zane, and Z. B. Popovic, "Recycling ambient microwave energy with broad-band rectenna arrays," IEEE Transactions on Microwave Theory and Techniques, vol. 52, no. 3, pp. 1014-1024, 2004. 